1 Universidade Federal do Recôncavo da Bahia (UFRB), Centro de Ciências da Saúde (CCS) - Santo Antônio de Jesus (BA), Brasil.

frandemetrio7@gmail.com

2 Universidade Federal da Bahia (UFBA), Instituto de Saúde Coletiva (ISC) Salvador (BA), Brasil.

\section{O Itinerário Terapêutico no Brasil: revisão sistemática e metassíntese a partir das concepções negativa e positiva de saúde}

\author{
The Therapeutic Itinerary in Brazil: systematic review and meta- \\ synthesis from the health negative and positive conceptions of health
}

Fran Demétrio', Elvira Rodrigues de Santana ${ }^{2}$, Marcos Pereira-Santos ${ }^{\mathbf{2}}$

DOI: 10.1590/0103-11042019S716

RESUMO A compreensão de como as pessoas procuram ajuda para resolver suas demandas ou problemas de saúde tem sido cada vez mais o foco de pesquisas. Objetiva-se analisar a produção científica nacional que aborda os Itinerários Terapêuticos (IT) a partir das concepções negativa e positiva de saúde. Foram pesquisados estudos na Biblioteca Virtual em Saúde, no período de 2008 a 2019. O metaestudo teve como objetivo interpretar e resumir os resultados. Foram identificados 224 estudos, e 50 foram selecionados. $\mathrm{O}$ principal núcleo de interesse na abordagem teórica considerou a doença/problema como disparador para a busca de terapêutica. Observa-se o predomínio de estudos com alto rigor metodológico e que usaram entrevistas e análise de conteúdo para produção de dados. Os resultados dos estudos revelam os sentidos que os sujeitos atribuem ao processo saúde-doença-cuidado. Entre as redes de apoio aos IT, destacam-se a família e os serviços de saúde. A resolutividade do sistema formal e a integralidade do cuidado também foram analisadas. Conclui-se que a ampliação de referenciais de análise e as perspectivas teóricas nos estudos sobre IT, a exemplo da concepção positiva de saúde, podem contribuir para a efetividade da integralidade e a eficácia simbólica no cuidado em saúde.

PALAVRAS-CHAVE Atitude frente a saúde. Acesso aos serviços de saúde. Sistemas de saúde.

ABSTRACT The understanding of how people look for help to solve their demands or health problems has increasingly been the focus of researches. The objective is to analyze national scientific production that addresses the Therapeutic Itineraries (TI) in Brazil from the negative and positive conceptions of health. Studies from the period between 2008 and 2019 were investigated on the Virtual Library in Health. The meta-study had the objective of interpreting and summarizing the results. 224 studies were identified, and 50 were selected. The main core of interest in the theoretical approach deemed the disease/problem as the trigger to the quest for treatment. It was noticed the dominance of studies with high methodological accuracy that used interviews and content analysis for data production. The results of the studies indicate the meaning that the subjects attach to the health-disease-care process. Among the IT support networks, the family and the healthcare services are emphasized. The formal system resolvability and care comprehensiveness were also analyzed. It is concluded that the expansion of analytical frameworks and theoretical perspectives on IT studies, such as the positive conception of health, can contribute to the effectiveness of comprehensiveness and symbolic effectiveness in health care.

KEYWORDS Attitude to health. Health services accessibility. Healthcare systems. 


\section{Introdução}

Os caminhos percorridos por pessoas na busca de cuidados terapêuticos para seus problemas de saúde são definidos pela literatura socioantropológica como Itinerários Terapêuticos (IT)' 1 .

Os estudos sobre IT adquiriram importância ao chamar a atenção para os fatores extrabiólogicos da doença. Dessa maneira, estudiosos da socioantropologia da saúde passaram a sugerir distintas classificações de sistemas terapêuticos na tentativa de ordenar as diferentes interpretações sobre as doenças e os processos de tratamento entre as várias alternativas disponíveis em uma dada sociedade ${ }^{1}$. Nesse sentido, o uso do conhecimento sobre IT pode oferecer elementos teórico-práticos capazes de proporcionar maior diálogo entre a clínica e a biografia dos sujeitos, com vistas a atos de saúde interpretativos e compreensivos que levem em conta esses e outros aspectos da história pessoal, sociocultural e do adoecimento.

Sem dúvida, são reconhecidos os importantes avanços teóricos e científicos ocorridos recentemente na investigação sobre os IT e suas implicações diante dos enfoques biologicista e reducionista no cuidado em saúde-doença.

Não obstante, os empreendimentos científicos realizados por expoentes da socioantropologia da saúde, no sentido de distinguirem as categorias doença e enfermidade, incorporando a esta última os múltiplos sentidos e significados do corpo-adoecido, transformando-os em sintomas e eventos preenchidos por signos do contexto social, cultural e político - categoria enfermidade -, bem como as tentativas de integração dos diversos componentes dos sistemas de cuidado à saúde e seus respectivos modelos explicativos, não têm sido inter e transdisciplinares o suficiente para ampliar a noção de saúde ${ }^{\mathbf{1}}$ de itinerário de cuidados para além da ausência de enfermidade.

Assim, a noção negativa de saúde e de itinerário terapêutico, caracterizada pela ênfase na doença ou enfermidade e na escolha de tratamentos para a sua cura, não está presente somente na epistemologia da biomedicina, mas também nas ciências sociais e humanas em saúde ${ }^{2,3}$.

Nesse sentido, os sistemas de saúde de alguns países, entre eles, o brasileiro, têm sido questionados por sua dependência com relação a um modelo assistencial individualista com ênfase na dimensão medicalizadora, hospitalocêntrica e curativista da doença, além dos elevados custos gerados e da baixa efetividade das formas de produção do cuidado'.

A cultura de produção da saúde caracterizada pela medicalização tem reduzido a condição do enfermo ao nível biológico individual, desconsiderando a sua dimensão subjetiva, humana, política, histórica, cultural e social ${ }^{4}$.

Nesse contexto, há uma necessidade de superar o paradigma biomédico hegemônico na perspectiva da construção de outras racionalidades em saúde, no que diz respeito à integralidade do cuidado, de modo que integrem os valores subjetivos do sujeito, sua autonomia e vivências socioculturais aos princípios que orientam as práticas em saúde, sobretudo no âmbito do Sistema Único de Saúde (SUS) ${ }^{\mathbf{5}}$.

A concepção negativa de saúde, correspondente à noção de 'ausência de doença', sustentada no paradigma biomédico, tem sido amplamente criticada, principalmente no que se refere ao problema epistemológico desse paradigma, o qual remonta a uma teoria empiricista e de reificação da doença. Em consequência, verificam-se algumas distorções geradas ao sistema de saúde e à sociedade, decorrentes, essencialmente, da centralização na doença ${ }^{6}$. A concepção de saúde como ausência de doenças, considerada por um prisma negativo, ainda que conceitualmente confortável e metodologicamente viável, de fato, não dá conta das múltiplas dimensões e dos complexos fenômenos que envolvem o processo saúde-doença-cuidado. Do mesmo modo que o todo é mais que a soma das partes, a saúde transpõe a noção de mera ausência ou o inverso da doença ${ }^{7}$.

Em contraponto a esses enfoques reducionistas, cresce o movimento sanitário pela 
promoção da saúde, baseada numa concepção positiva de saúde, cuja abordagem tem como principal característica a integração dos aspectos sociais, humanos, culturais, políticos, filosóficos e econômicos na explicação do processo saúde-doença. Por esse prisma, pretende-se ampliar a noção da prevenção de doenças e restaurar em toda sua plenitude os valores mais amplos da vida. Essa concepção parte de um pressuposto de que a saúde não é o oposto lógico da doença, e, por isso, é desejável que todos os indivíduos possam estender ao máximo suas aspirações, sem limitá-las à evitação de doenças ou à condição de adoecidos ${ }^{8,9}$.

Para Almeida-Filho ${ }^{7}$, os elementos da saúde e da doença não podem ser definidos essencialmente como uma questão clínica-individual ou biológica-subindividual. Segundo esse autor, uma importante possibilidade aberta à exploração epistemológica é a incorporação da diversidade de formas concretas de expressão da saúde, nos distintos planos, como, por exemplo, a noção de 'bem-estar' no plano individual, 'qualidade de vida' no plano microssocial e 'situação de saúde' no plano coletivo mais amplo. Nesse sentido, os objetos da saúde são polissêmicos, plurais e multifacetados, reclamando a necessidade de construção de um objeto-modelo positivo de conhecimento e de intervenção, e não um objeto negativo, o qual consiste em mero resquício conceitual de modos de explicação da vida biológica e social fundamentados em seu inverso lógico ${ }^{7}$.

Diante desse cenário, a preocupação com os caminhos percorridos por pessoas em busca de cuidados em saúde-doença tem sido considerada elemento importante na compreensão positiva da saúde ${ }^{4}$, uma vez que esses não necessariamente coincidem com esquemas ou fluxos pré-determinados ${ }^{7}$. Além disso, pode subsidiar processos de organização, planejamento e gestão de serviços de saúde, na construção de práticas cuidadoras compreensivas e contextualmente integradas ${ }^{10}$.

A partir dessa compreensão, os estudos sobre IT, ao abordarem o cuidado à saúde, $\mathrm{e}$ não apenas os cuidados médicos/terapêuticos à saúde, podem avançar na medida em que abordam os sistemas de cuidados pelo prisma da concepção positiva de saúde. Isso porque passam a considerar como elementos primordiais de estudo tanto a experiência de enfermidade como a de saúde, significadas em consonância com os distintos contextos socioculturais de vida, na avaliação, no planejamento, na organização e na gestão efetivos de serviços de atenção integral à saúde ${ }^{6,11}$.

Pelo exposto, o objetivo deste estudo é analisar a produção científica nacional que aborda os itinerários terapêuticos a partir das concepções negativa e positiva de saúde.

\section{Metodologia}

\section{Estratégias de busca e fontes de informações}

Trata-se de revisão sistemática e metassíntese da literatura que envolveu as etapas de identificação, fichamento, análise e interpretação de resultados de pesquisas. A revisão sistemática com metassíntese consiste numa estratégia metodológica usada na produção de evidências qualitativas e permite realizar uma leitura crítica das interpretações presentes nos estudos qualitativos, norteando-se por parâmetros metodológicos rigorosos, sistemáticos e objetivos ${ }^{12,13}$.

A busca dos estudos foi realizada em março de 2018 nas bases da Biblioteca Virtual em Saúde (Bireme), Scientific Electronic Library Online (SciELO) e Medical Literature Analysis and Retrievel System Online (Medline). As buscas foram atualizadas em setembro de 2019.

Para a seleção das publicações nas bases de dados, primeiramente, foi realizada uma etapa exploratória para identificação dos Descritores em Ciências da Saúde (DeCS) a serem utilizados. Elegeu-se o termo itinerário terapêutico para pesquisa, no entanto, o termo não foi localizado no DeCS. Então, optou-se pelos seguintes descritores: 'itinerários terapêuticos'; 'itinerários de cuidado'; 
'trajetórias terapêuticas'; 'trajetórias de tratamento'; 'trajetória do cuidado'; ‘trajetória do paciente' e seus equivalentes em inglês e espanhol.

Os resultados das buscas foram gerenciados no programa Mendeley para remoção das duplicatas e aplicação dos critérios de inclusão. $O$ processo de triagem foi realizado por autores independentes (ERS e MP-S), utilizando formulário com os critérios de elegibilidade dos artigos. Discordâncias quanto à inclusão foram resolucionadas por meio de consenso com um terceiro revisor (FD).

\section{Critérios de elegibilidade}

Foram considerados elegíveis os estudos brasileiros de cunho qualitativo que versassem sobre o IT, publicados entre 2008 a 2019. Esse recorte temporal levou em consideração o fato de ter sido identificada na literatura específica uma sistematização da produção científica sobre IT referente ao período de 1989 a $2008^{10}$. Os critérios de exclusão consideraram: estudos quantitativos, artigos de revisão, capítulos de livros e artigos que abordavam apenas a experiência de adoecimento.

Figura 1. Fluxograma de seleção dos artigos

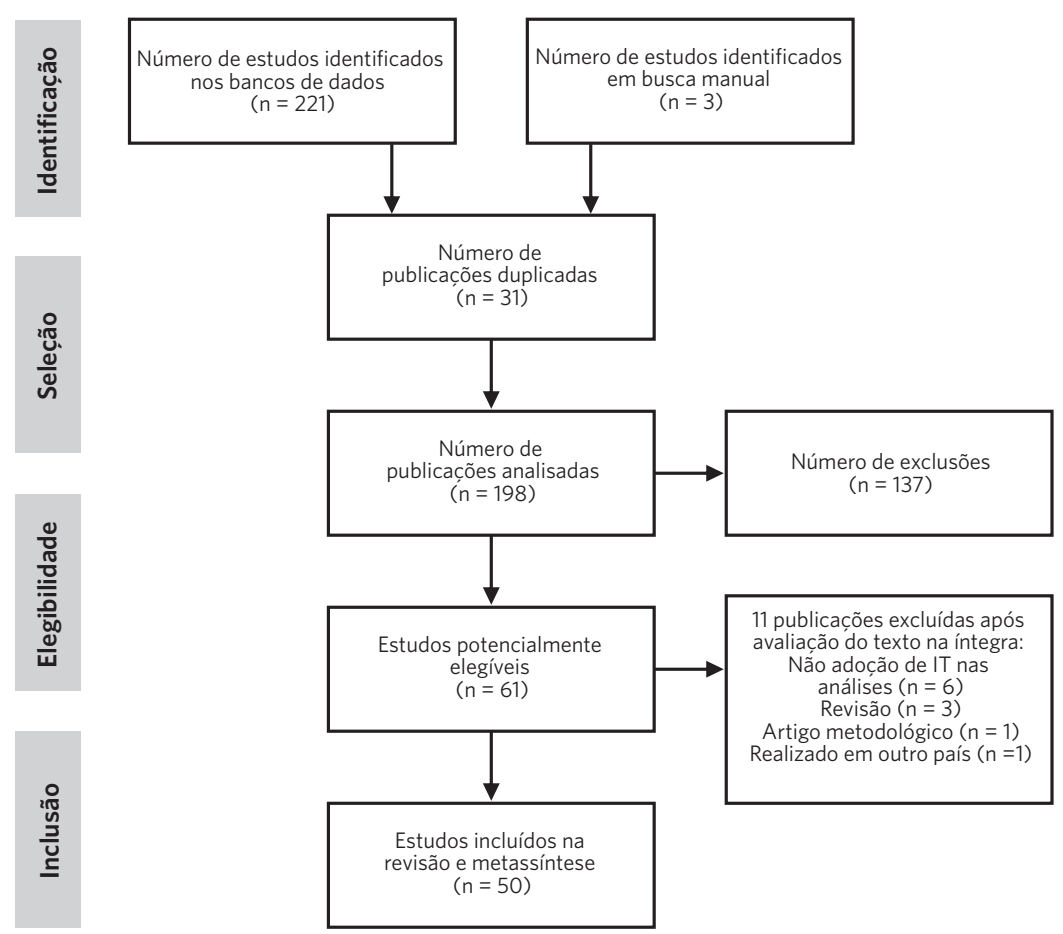

\section{Extração dos dados}

Os artigos selecionados foram sistematizados em planilha contendo as seguintes informações: ano de divulgação; o título do periódico que publicou o estudo; local de realização do estudo. Com relação às características temáticas e metodológicas, identificaram-se os participantes da pesquisa; a abordagem do estudo; e a abordagem metodológica utilizada na produção de dados. 


\section{Avaliação do rigor metodológico}

Para a avaliação dos estudos qualitativos, foi utilizado o instrumento proposto pelo Critical Appraisal Skills Programme (Casp) ${ }^{\mathbf{1 4}}$, uma vez que auxilia na análise crítica de relatos de pesquisas qualitativas. Esse instrumento apresenta dez questões que conduzem o avaliador a pensar de forma sistemática sobre o rigor, a credibilidade e a relevância do estudo, considerando: (1) objetivo claro e justificado, (2) desenho metodológico apropriado aos objetivos, (3) procedimentos metodológicos apresentados e discutidos, (4) seleção da amostra, (5) coleta de dados descrita, instrumentos e processo de saturação explicitados, (6) relação entre pesquisador e pesquisado, (7) cuidados éticos, (8) análise densa e fundamentada, (9) resultados apresentados e discutidos, apontando o aspecto da credibilidade e uso da triangulação, (10) descrição sobre as contribuições e implicações do conhecimento gerado pela pesquisa, bem como suas limitações ${ }^{\mathbf{1 4}}$.

Os artigos foram pontuados em cada critério como: 1 - se o critério foi atendido; 0 - se o critério não foi atendido; 0,5 - se o critério foi parcialmente atendido ${ }^{14}$. A pontuação máxima para um trabalho foi 10. Os estudos foram classificados em duas categorias: na categoria A, foram classificados os estudos com alto rigor metodológico, uma vez que preencheram ao menos nove dos dez itens; na categoria $\mathrm{B}$, foram classificados os estudos com moderado rigor metodológico, quando pelo menos 5 dos 10 itens foram atendidos ${ }^{14,15}$.

\section{Análise de dados}

Entre as diferentes abordagens para a construção de metassínteses, o metaestudo se destaca para análises de grande número de estudos e por estimular a cooperação e o trabalho conjunto entre pesquisadores ${ }^{16}$. Dessa maneira, na proposta metodológica do metaestudo, privilegiou-se: na metateoria, a análise sobre os problemas, conceitos e teorias que levaram os pesquisadores a explorar determinadas questões; no metamétodo, a análise da abordagem metodológica adotada nos estudos e de suas consequências para a perspectiva lançada sobre os temas investigados; na meta-análise dos dados, busca-se confrontar as interpretações realizadas nos estudos revisados, reinterpretando os dados à luz dos achados dos demais estudos que compuseram o universo bibliográfico investigado ${ }^{16}$.

\section{Resultados}

As estratégias de busca estão apresentadas na figura 1. Identificaram-se 221 artigos nas bases de dados, sendo 66 indexados na base SciELO, 77 na Bireme, 78 na Medline e 3 por busca manual. De acordo com os critérios de elegibilidade, 56 estudos foram selecionados para avaliação de elegibilidade, e 5011,17-64 foram selecionados para integrar o corpus desta metassíntese (quadro 1). Os motivos para exclusão dos artigos foram não adoção de IT nas análises ${ }^{6}$, estudos de revisão ${ }^{3}$, estudo metodológico ${ }^{1}$ e realização em outro país ${ }^{11}$.

No que diz respeito à publicação de estudos sobre IT, independentemente da concepção de saúde que orientou as pesquisas, observou-se uma concentração maior de estudos na região Sudeste (34\%) e Sul (26\%) do Brasil. A região Nordeste apresentou o terceiro posicionamento no quantitativo de estudos (20\%), e o Centro-oeste $10 \%$. A região Norte apresentou apenas uma publicação (gráfico 1; quadro 1). 
Gráfico 1. Região de realização dos estudos selecionados para revisão e metassíntese sobre itinerários terapêuticos no Brasil (2008-2019)

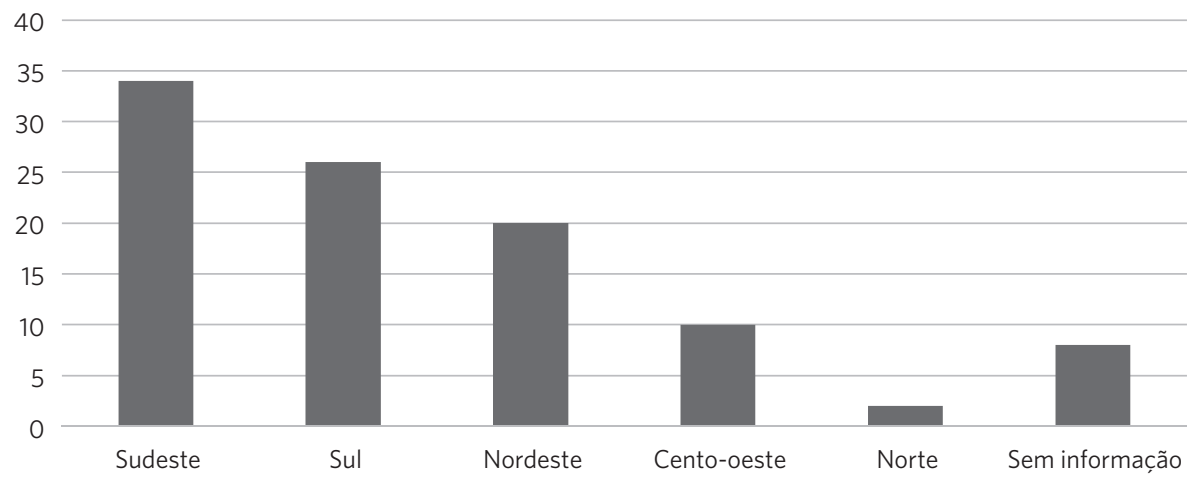

Quadro 1. Características metodológicas dos estudos selecionados para revisão sistemática sobre Itinerários Terapêuticos no Brasil (2008-2019)

\begin{tabular}{|c|c|c|c|c|c|}
\hline Autores/ano & $\begin{array}{l}\text { Local de estudo/ } \\
\text { Região }\end{array}$ & Sujeito da pesquisa & $\begin{array}{l}\text { Procedimento de } \\
\text { coleta de dados }\end{array}$ & $\begin{array}{l}\text { Análise de dados/ } \\
\text { Software }\end{array}$ & $\begin{array}{l}\text { Referencial } \\
\text { Teórico adotado }\end{array}$ \\
\hline $\begin{array}{l}\text { Andrade e Viera } \\
\text { (2018) }\end{array}$ & São Paulo & $\begin{array}{l}\text { Mulheres acometidas por morbidade } \\
\text { materna grave }\end{array}$ & $\begin{array}{l}\text { Entrevista se- } \\
\text { miestruturada }\end{array}$ & $\begin{array}{l}\text { Análise de Conteúdo (Go- } \\
\text { mes, 2010) }\end{array}$ & Kleinman (1978) \\
\hline $\begin{array}{l}\text { Amaral et al. } \\
(2012)\end{array}$ & Florianópolis/SC & Puérperas & $\begin{array}{l}\text { Entrevista se- } \\
\text { miestruturada }\end{array}$ & Atlas-Ti 5.0 & Kleinman (1978) \\
\hline $\begin{array}{l}\text { Bomfim et al. } \\
\text { (2014) }\end{array}$ & Rio de Janeiro/RJ & Gestantes & $\begin{array}{l}\text { Entrevista se- } \\
\text { miestruturada }\end{array}$ & $\begin{array}{l}\text { Análise do conteúdo (Bar- } \\
\text { din, 1977) }\end{array}$ & $\begin{array}{l}\text { Alves e Souza } \\
(1999)\end{array}$ \\
\hline $\begin{array}{l}\text { Burille e Gerhardt } \\
\text { (2014) }\end{array}$ & $\begin{array}{l}\text { Rincão dos Maia, } \\
\text { Canguçu/RS }\end{array}$ & Homens rurais & $\begin{array}{l}\text { Entrevistas se- } \\
\text { miestruturadas e } \\
\text { grupo focal }\end{array}$ & $\begin{array}{l}\text { NVivo8; SmartDraw-2009; } \\
\text { análise temática proposta } \\
\text { por Minayo (2010) }\end{array}$ & Não menciona \\
\hline Guerin (2012) & Porto Alegre/RS & $\begin{array}{l}\text { Usuários de uma Unidade de Estraté- } \\
\text { gia de Saúde da Família }\end{array}$ & $\begin{array}{l}\text { Questionário } \\
\text { semiestruturado }\end{array}$ & $\begin{array}{l}\text { Análise do conteúdo (Ri- } \\
\text { chardson, 1999) }\end{array}$ & Kleinman (1978) \\
\hline $\begin{array}{l}\text { Carneiro et al. } \\
(2017)\end{array}$ & Belém/PR & Pacientes que vivem com Hanseníase & $\begin{array}{l}\text { Entrevista se- } \\
\text { miestruturada }\end{array}$ & $\begin{array}{l}\text { Análise de conteúdo (Bar- } \\
\text { din, 2011) }\end{array}$ & Não menciona \\
\hline $\begin{array}{l}\text { Carvalho et al. } \\
\text { (2016) }\end{array}$ & $\begin{array}{l}\text { Belo Horizonte/ } \\
\text { MG }\end{array}$ & $\begin{array}{l}\text { Pacientes com anorexias e bulimias } \\
\text { nervosas }\end{array}$ & Entrevistas & Não menciona & Não menciona \\
\hline $\begin{array}{l}\text { Cerqueira et al. } \\
\text { (2016) }\end{array}$ & $\begin{array}{l}\text { Feira de Santana/ } \\
\text { BA }\end{array}$ & $\begin{array}{l}\text { Mães das crianças com deficiência } \\
\text { intelectual }\end{array}$ & $\begin{array}{l}\text { Entrevista se- } \\
\text { miestruturada }\end{array}$ & $\begin{array}{l}\text { Análise de conteúdo (Bar- } \\
\text { din, 2011) }\end{array}$ & Não menciona \\
\hline $\begin{array}{l}\text { Conill et al. } \\
\text { (2008) }\end{array}$ & Florianópolis/SC & $\begin{array}{l}\text { Usuários dos serviços da saúde suple- } \\
\text { mentar que tiveram Infarto Agudo do } \\
\text { Miocárdio/IAM, mulheres com câncer } \\
\text { de mama, pessoas com alcoolismo e } \\
\text { mulheres que haviam dado à luz há } \\
\text { até um ano e meio }\end{array}$ & Entrevistas & $\begin{array}{l}\text { Análise temática; } \\
\text { Nvivo }\end{array}$ & $\begin{array}{l}\text { Kleinman (1978); } \\
\text { Alves e Souza } \\
\text { (1999) }\end{array}$ \\
\hline $\begin{array}{l}\text { Coqueiro et al. } \\
\text { (2018) }\end{array}$ & Serra/ES & $\begin{array}{l}\text { Sujeitos que convivem com o diabetes } \\
\text { mellitus. }\end{array}$ & $\begin{array}{l}\text { Entrevista nar- } \\
\text { rativa }\end{array}$ & $\begin{array}{l}\text { Análise institucional (Ba- } \\
\text { remblitt, 2012) }\end{array}$ & Baremblitt (2012) \\
\hline $\begin{array}{l}\text { Cordeiro et al. } \\
\text { (2013) }\end{array}$ & Salvador/Ba & 2 pessoas com anemia falciforme & $\begin{array}{l}\text { Entrevista se- } \\
\text { miestruturada }\end{array}$ & $\begin{array}{l}\text { Análise de conteúdo te- } \\
\text { mática }\end{array}$ & $\begin{array}{l}\text { Kleinman (1978); } \\
\text { Alves e Souza } \\
\text { (1999) }\end{array}$ \\
\hline $\begin{array}{l}\text { Corrêa et al. } \\
\text { (2011) }\end{array}$ & Cuiabá/MT & $\begin{array}{l}\text { Idosa em condição crônica por sofri- } \\
\text { mento psíquico e sua família }\end{array}$ & $\begin{array}{l}\text { Entrevista em } \\
\text { profundidade }\end{array}$ & Genograma & Não menciona \\
\hline $\begin{array}{l}\text { Eckhardt e Raupp } \\
\text { (2017) }\end{array}$ & $\begin{array}{l}\text { Rio Grande do } \\
\text { Sul/RS }\end{array}$ & Usuário ou ex-usuário de drogas & $\begin{array}{l}\text { Entrevistas se- } \\
\text { miestruturadas }\end{array}$ & $\begin{array}{l}\text { Análise de Conteúdo (Bar- } \\
\text { din, 2009) }\end{array}$ & Não menciona \\
\hline
\end{tabular}


Quadro 1. (cont.)

\begin{tabular}{|c|c|c|c|c|c|}
\hline $\begin{array}{l}\text { Fausto et al. } \\
\text { (2017) }\end{array}$ & $\begin{array}{l}\text { Petrolina/PE e } \\
\text { Juazeiro/BA }\end{array}$ & $\begin{array}{l}\text { Pacientes acometidos por acidente } \\
\text { vascular encefálico (AVE) }\end{array}$ & $\begin{array}{l}\text { Entrevista se- } \\
\text { miestruturada }\end{array}$ & Não menciona & Não menciona \\
\hline $\begin{array}{l}\text { Favero-Nunes e } \\
\text { Santos (2010) }\end{array}$ & Não menciona & $\begin{array}{l}\text { Mães de crianças com transtorno } \\
\text { autístico }\end{array}$ & $\begin{array}{l}\text { Entrevista se- } \\
\text { miestruturada }\end{array}$ & $\begin{array}{l}\text { Método clínico qualitativo } \\
\text { proposto por Turato (2003); } \\
\text { Análise temática (Bardin, } \\
\text { 1988; Triviños, 1992) }\end{array}$ & Não menciona \\
\hline $\begin{array}{l}\text { Ferreira e Silva } \\
\text { (2012) }\end{array}$ & Juiz de Fora/MG & Homens e mulheres com o vírus HIV & Entrevista & $\begin{array}{l}\text { Análise temática (Bardin, } \\
\text { 2008) }\end{array}$ & Não menciona \\
\hline $\begin{array}{l}\text { Ferreira e Espírito } \\
\text { Santo (2012) }\end{array}$ & Manguinhos/RJ & $\begin{array}{l}\text { Moradores de cada comunidade de } \\
\text { Manguinhos }\end{array}$ & $\begin{array}{l}\text { Entrevistas se- } \\
\text { midiretivas se- } \\
\text { guindo um roteiro } \\
\text { etnográfico }\end{array}$ & Não menciona & $\begin{array}{l}\text { Augé (1984); } \\
\text { Alves e Souza } \\
\text { (1999); } \\
\text { Massé (1985) }\end{array}$ \\
\hline $\begin{array}{l}\text { Finco e Bertoncini } \\
\text { (2016) }\end{array}$ & $\begin{array}{l}\text { Santa Catarina/ } \\
\text { RS }\end{array}$ & $\begin{array}{l}\text { Adolescentes com diabetes mellitus } \\
\text { tipo } 1 \text { e seus familiares }\end{array}$ & Entrevista aberta & $\begin{array}{l}\text { Análise do conteúdo (Bar- } \\
\text { din, 2014) }\end{array}$ & Não menciona \\
\hline $\begin{array}{l}\text { Fundato et al. } \\
\text { (2012) }\end{array}$ & São Paulo/SP & $\begin{array}{l}\text { Adolescentes e Adultos Jovens com } \\
\text { Osteossarcoma }\end{array}$ & $\begin{array}{l}\text { Entrevista orien- } \\
\text { tada por um } \\
\text { questionário }\end{array}$ & $\begin{array}{l}\text { Análise de conteúdo (Bar- } \\
\text { din, 2012) }\end{array}$ & Kleinman (1978); \\
\hline $\begin{array}{l}\text { Mângia e Yasu- } \\
\text { taki (2008) }\end{array}$ & Santo André/SP & $\begin{array}{l}\text { Usuários do serviço de saúde mental e } \\
\text { de pessoas de suas redes sociais }\end{array}$ & $\begin{array}{l}\text { Análise docu- } \\
\text { mental e pesqui- } \\
\text { sa bibliográfica, } \\
\text { elaboração de } \\
\text { diário de campo e } \\
\text { entrevista }\end{array}$ & Não menciona & $\begin{array}{l}\text { Alves e Souza } \\
\text { (1993) }\end{array}$ \\
\hline $\begin{array}{l}\text { Muñoz et al. } \\
\text { (2018) }\end{array}$ & João Pessoa/PR & $\begin{array}{l}\text { Pessoas com diagnóstico de fibro- } \\
\text { mialgia }\end{array}$ & $\begin{array}{l}\text { Entrevista não } \\
\text { diretiva }\end{array}$ & $\begin{array}{l}\text { Análise de conteúdo (Bar- } \\
\text { din,1977) }\end{array}$ & $\begin{array}{l}\text { Guest et al. } \\
\text { (2006) }\end{array}$ \\
\hline $\begin{array}{l}\text { Landim et al. } \\
\text { (2016) }\end{array}$ & $\begin{array}{l}\text { Município do } \\
\text { interior da Bahia } \\
\text { (Não menciona } \\
\text { o nome do muni- } \\
\text { cípio) }\end{array}$ & $\begin{array}{l}\text { Gestantes que referiram óbito fetal ou } \\
\text { neonatal }\end{array}$ & $\begin{array}{l}\text { Entrevista em } \\
\text { profundidade }\end{array}$ & $\begin{array}{l}\text { Análise de Conteúdo (Bar- } \\
\text { din, 2011) }\end{array}$ & Não menciona \\
\hline $\begin{array}{l}\text { Marques e Mân- } \\
\text { gia (2013) }\end{array}$ & $\begin{array}{l}\text { Santana de Par- } \\
\text { naíba/SP }\end{array}$ & Usuários de álcool & $\begin{array}{l}\text { Grupo focal; } \\
\text { Entrevista (não } \\
\text { há especificação } \\
\text { do tipo de entre- } \\
\text { vista) }\end{array}$ & $\begin{array}{l}\text { Análise de enunciação e } \\
\text { análise temática }\end{array}$ & $\begin{array}{l}\text { Alves e Souza } \\
\text { (1999); Alves } \\
\text { (2006) }\end{array}$ \\
\hline Rosa et al. (2011) & $\begin{array}{l}\text { Santa Catarina/ } \\
\text { RS }\end{array}$ & $\begin{array}{l}\text { Homens ou mulheres em tratamento } \\
\text { quimioterápico }\end{array}$ & $\begin{array}{l}\text { Entrevista se- } \\
\text { miestruturada }\end{array}$ & $\begin{array}{l}\text { Análise de conteúdo (Bar- } \\
\text { din, 2006) }\end{array}$ & $\begin{array}{l}\text { Kleinman (1980); } \\
\text { Orem (1980) }\end{array}$ \\
\hline $\begin{array}{l}\text { Martins e Iriart } \\
\text { (2014) }\end{array}$ & Salvador/BA & Pacientes com Hanseníase & $\begin{array}{l}\text { Entrevistas em } \\
\text { profundidade }\end{array}$ & $\begin{array}{l}\text { Análise de narrativa Bury } \\
\text { (2001) }\end{array}$ & $\begin{array}{l}\text { Alves e Souza } \\
\text { (1999); Alves } \\
\text { (2006); Souza } \\
\text { (1999) }\end{array}$ \\
\hline $\begin{array}{l}\text { Musquim et al. } \\
\text { (2013) }\end{array}$ & Cuiabá/MT & $\begin{array}{l}\text { Família em condição de adoecimento } \\
\text { crônico }\end{array}$ & $\begin{array}{l}\text { Entrevista em } \\
\text { profundidade }\end{array}$ & $\begin{array}{l}\text { Software Microsoft Power } \\
\text { Point } 2007\end{array}$ & Não menciona \\
\hline $\begin{array}{l}\text { Nabão e Maruya- } \\
\text { ma (2009) }\end{array}$ & Marcelândia/MT & $\begin{array}{l}\text { Uma pessoa que foi acometida por } \\
\text { um infarto }\end{array}$ & $\begin{array}{l}\text { Entrevista em } \\
\text { profundidade }\end{array}$ & $\begin{array}{l}\text { Análise temática (Minayo, } \\
\text { 2006) }\end{array}$ & $\begin{array}{l}\text { Alves e Souza } \\
(1999) ; \text { Kleinman } \\
(1980)\end{array}$ \\
\hline $\begin{array}{l}\text { Neves e Nunes } \\
\text { (2010) }\end{array}$ & Não menciona & Trabalhadores com LER/DORT & $\begin{array}{l}\text { Entrevistas em } \\
\text { profundidade }\end{array}$ & $\begin{array}{l}\text { Análise temática (Jovche- } \\
\text { lovitch, 2002) }\end{array}$ & Não menciona \\
\hline $\begin{array}{l}\text { Nogueira et al. } \\
\text { (20160 }\end{array}$ & Jacareacanga/PR & Indígenas Munduruku & $\begin{array}{l}\text { Entrevistas se- } \\
\text { miestruturadas }\end{array}$ & $\begin{array}{l}\text { Análise de conteúdo (Bar- } \\
\text { din, 2009) }\end{array}$ & $\begin{array}{l}\text { Alves e Souza } \\
\text { (1999); }\end{array}$ \\
\hline $\begin{array}{l}\text { Pereira et al. } \\
(2014)\end{array}$ & $\begin{array}{l}\text { Região Metropo- } \\
\text { litana do Rio de } \\
\text { Janeiro }\end{array}$ & Adolescentes usuários de um CAPSi & $\begin{array}{l}\text { Entrevista (não } \\
\text { há especificação } \\
\text { do tipo de entre- } \\
\text { vista) }\end{array}$ & Não menciona & $\begin{array}{l}\text { Kaës }(1982 ; \\
2005)\end{array}$ \\
\hline $\begin{array}{l}\text { Pinho e Pereira } \\
\text { (2012) }\end{array}$ & São Paulo/SP & $\begin{array}{l}\text { Usuários do Centro de Referência e } \\
\text { Treinamento em DST/Aids (CRT) }\end{array}$ & Etnografia & Não menciona & $\begin{array}{l}\text { (Alves e Souza, } \\
\text { 1999) }\end{array}$ \\
\hline
\end{tabular}


Quadro 1. (cont.)

\begin{tabular}{|c|c|c|c|c|c|}
\hline $\begin{array}{l}\text { Ribeiro et al. } \\
\text { (2011) }\end{array}$ & Minas Gerais & $\begin{array}{l}\text { Mulheres em tratamento para o cân- } \\
\text { cer do colo do útero }\end{array}$ & Entrevista aberta & Não menciona & Não menciona \\
\hline Portugal (2016) & Não menciona & Participantes do terreiro & $\begin{array}{l}\text { Entrevistas se- } \\
\text { miestruturadas }\end{array}$ & $\begin{array}{l}\text { Análise de conteúdo (Bar- } \\
\text { din, 1977) }\end{array}$ & Kleinman (1980) \\
\hline $\begin{array}{l}\text { Rodrigues e Mak- } \\
\text { sud (2017) }\end{array}$ & Rio de Janeiro/RJ & Pacientes com HIV/Aids & $\begin{array}{l}\text { Diário de campo, } \\
\text { conversas infor- } \\
\text { mais e entrevistas }\end{array}$ & Análise de conteúdo & Não mencionam \\
\hline $\begin{array}{l}\text { Rosa e Radünz } \\
\text { (2013) }\end{array}$ & $\begin{array}{l}\text { Santa Catarina/ } \\
\text { RS }\end{array}$ & Mulheres com câncer de mama & $\begin{array}{l}\text { Entrevista se- } \\
\text { miestruturada }\end{array}$ & $\begin{array}{l}\text { Análise do Conteúdo } \\
\text { (2006) }\end{array}$ & Kleinman (1980) \\
\hline $\begin{array}{l}\text { Santos e Silva } \\
(2014)\end{array}$ & Goiás & Famílias de comunidades quilombolas & $\begin{array}{l}\text { Questionário fa- } \\
\text { miliar e entrevista } \\
\text { semiestruturada }\end{array}$ & Segundo eixos temáticos & Não menciona \\
\hline $\begin{array}{l}\text { Scheffer et al. } \\
\text { (2012) }\end{array}$ & Não menciona & $\begin{array}{l}\text { Sujeitos com prescrição médica para } \\
\text { uso de Aparelho de Amplificação } \\
\text { Sonora Individual }\end{array}$ & Entrevistas & $\begin{array}{l}\text { A análise dos dados seguiu } \\
\text { o caminho proposto por } \\
\text { Minayo (1994) }\end{array}$ & Não menciona \\
\hline $\begin{array}{l}\text { Segata e Segata } \\
\text { (2011) }\end{array}$ & $\begin{array}{l}\text { Alto Vale do } \\
\text { Itajaí/ RS }\end{array}$ & $\begin{array}{l}\text { Pessoas da comunidade do Alto do } \\
\text { Vale do Itajaí }\end{array}$ & $\begin{array}{l}\text { Etnografia, nar- } \\
\text { rativas, diário de } \\
\text { campo }\end{array}$ & Não menciona & Não menciona \\
\hline Silva et al. (2014) & Rio Grande do Sul & Pessoas acometidas por úlcera venosa & $\begin{array}{l}\text { Entrevista se- } \\
\text { miestruturada }\end{array}$ & $\begin{array}{l}\text { Análise de conteúdo (Bar- } \\
\text { din, 2011) }\end{array}$ & Não menciona \\
\hline Silva et al. (2015) & Salvador/BA & $\begin{array}{l}\text { Homens com sorologia positiva para } \\
\text { HIV }\end{array}$ & $\begin{array}{l}\text { Entrevistas se- } \\
\text { miestruturadas }\end{array}$ & $\begin{array}{l}\text { QSR Nvivo; Linhas narrati- } \\
\text { vas (Spink e Lima, 1999) }\end{array}$ & Não menciona \\
\hline Silva et al. (2016) & $\begin{array}{l}\text { Rio de Janeiro e } \\
\text { São Paulo }\end{array}$ & $\begin{array}{l}\text { Homens em tratamento de IST e que } \\
\text { não apresentavam suspeita ou diag- } \\
\text { nóstico de ISTs }\end{array}$ & $\begin{array}{l}\text { Entrevista se- } \\
\text { miestruturada }\end{array}$ & $\begin{array}{l}\text { Análise de discurso (Pê- } \\
\text { cheux, 2006) }\end{array}$ & $\begin{array}{l}\text { Alves e Souza } \\
\text { (1999); Silva e } \\
\text { Sancho (2013) }\end{array}$ \\
\hline $\begin{array}{l}\text { Sisson et al. } \\
\text { (2011) }\end{array}$ & $\begin{array}{l}\text { Porto Alegre, } \\
\text { Florianópolis e } \\
\text { Curitiba (RS) }\end{array}$ & $\begin{array}{l}\text { Usuários de planos de saúde que } \\
\text { receberam cuidados em infarto agudo } \\
\text { do miocárdio, alcoolismo, câncer de } \\
\text { mama e parto }\end{array}$ & $\begin{array}{l}\text { Entrevistas se- } \\
\text { miestruturadas }\end{array}$ & $\begin{array}{l}\text { Análise temática de Bardin } \\
\text { (Minayo, 2007); software } \\
\text { Nvivo }\end{array}$ & Não menciona \\
\hline Trad et al. (2010) & Salvador/Ba & Famílias de classe popular & $\begin{array}{l}\text { Etnografia; entre- } \\
\text { vistas semiestru- } \\
\text { turadas }\end{array}$ & $\begin{array}{l}\text { Antropologia interpretativa } \\
\text { (Geertz, 1989); Genogra- } \\
\text { mas familiares (Cerveny, } \\
\text { 2001) }\end{array}$ & Não menciona \\
\hline Scott et al. (2018) & Pernambuco & $\begin{array}{l}\text { Cuidadoras de filhos com Síndrome } \\
\text { Congênita do Zika }\end{array}$ & Etnografia & Não menciona & Alves (2015) \\
\hline $\begin{array}{l}\text { Souza et al. } \\
(2014)\end{array}$ & Rio Grande do Sul & Travestis & $\begin{array}{l}\text { Etnografia; ob- } \\
\text { servação partici- } \\
\text { pante, entrevistas } \\
\text { em profundidade } \\
\text { e acompanha- } \\
\text { mento da vida } \\
\text { cotidiana }\end{array}$ & $\begin{array}{l}\text { Análise antropológica } \\
\text { (Geertz, 1989) }\end{array}$ & Não menciona \\
\hline $\begin{array}{l}\text { Thaines et al. } \\
\text { (2009) }\end{array}$ & Sorriso/MT & $\begin{array}{l}\text { Usuários do serviço de saúde com } \\
\text { Diabetes mellitus }\end{array}$ & $\begin{array}{l}\text { Entrevista em } \\
\text { profundidade }\end{array}$ & Não menciona & Não menciona \\
\hline $\begin{array}{l}\text { Valdanha-Or- } \\
\text { nelas e Santos } \\
(2016)\end{array}$ & Ribeirão Preto/SP & $\begin{array}{l}\text { Mães de jovens diagnosticados(as) } \\
\text { com Anorexia nervosa }\end{array}$ & $\begin{array}{l}\text { Entrevistas se- } \\
\text { miestruturadas }\end{array}$ & $\begin{array}{l}\text { A análise de conteúdo } \\
\text { temática (Bogdan e Biklen, } \\
\text { 1994) }\end{array}$ & Não menciona \\
\hline Vale et al. (2015) & $\begin{array}{l}\text { Feira de Santana/ } \\
\text { BA }\end{array}$ & Feirantes & $\begin{array}{l}\text { Entrevistas se- } \\
\text { miestruturadas }\end{array}$ & $\begin{array}{l}\text { Análise do conteúdo (Bar- } \\
\text { din , 2011) }\end{array}$ & Não menciona \\
\hline $\begin{array}{l}\text { Vale e Vecchia } \\
\text { (2019) }\end{array}$ & Minas Gerais & População em situação de rua & $\begin{array}{l}\text { Observação } \\
\text { participante e } \\
\text { entrevistas se- } \\
\text { miestruturadas }\end{array}$ & $\begin{array}{l}\text { Análise do conteúdo (Bar- } \\
\text { din ,1977; Braun e Clarke, } \\
\text { 2006) }\end{array}$ & Alves (2016) \\
\hline $\begin{array}{l}\text { Visentin e Lenar- } \\
\text { dt (2010) }\end{array}$ & Curitiba/PR & Idosos em tratamento oncológico & $\begin{array}{l}\text { Entrevista se- } \\
\text { miestruturada }\end{array}$ & $\begin{array}{l}\text { Método de categorização } \\
\text { (Minayo, 2004) }\end{array}$ & Não menciona \\
\hline
\end{tabular}




\section{Análise metateórica}

O principal núcleo de interesse na abordagem teórica sobre IT dos estudos selecionados para essa revisão consideraram apenas a doença/problema como disparador para a busca de terapêuticas ${ }^{17-19,22-24,26,28,30,}$ $\mathbf{3 1 , 4 1 , 4 3 , 4 4 , 4 7 , 4 9 , 5 0 , 5 2 , 5 7 , 5 9 - 6 2 , 6 4}$, com exceção de alguns estudos $15,18,19,23,25,30-32,34-37,39,41,43,45,46$, 53-55,57,63, que buscaram conhecer os IT a partir de práticas cotidianas de cuidado à saúde. As doenças crônicas como: Diabetes Melittus, HIV-Aids, câncer, hipertensão arterial, entre outras, constituíram-se os objetos de investigação dos estudos ${ }^{19,22,24,28-34,36,37, ~}$ $41,43,46,47,49,54,57,61,62,64$, por serem doenças que demandam um longo período de tratamento, maior convivência com a enfermidade e permitirem que o itinerário seja delineado em uma diversidade de sistemas de cura e significações.

A maioria dos estudos 17,19,21,22-29,32-38, 40-44,48,49,51,52,54,56,57,59-63, com exceção de sete $\mathbf{1 8 , 2 9 , 3 7 , 4 5 , 4 8 , 5 3 , 6 4}$, teve como foco a experiência do sujeito adoecido, problematizando aspectos que atravessam a busca de tratamento, como questões culturais e sociais, gênero, a qualidade dos atendimentos e a organização dos serviços de saúde, terapias religiosas, entre outros.

A maior parte dos estudos 17,19, 22-24,26,2931,35, 41,42,46,49,52,58-62 focou a discussão sobre a instituição formal (serviços biomédicos de saúde) como principal rede de apoio para o tratamento da doença, e oito estudos $11,17,24,29,32,38,55,57$ utilizaram o modelo explicativo proposto por Kleiman (1980), que define os sistemas de cuidados em três setores ou subsistemas: o setor da cura profissional (professional sector) consiste nos profissionais da medicina científica ou de medicinas tradicionais (como a chinesa); o setor das curas populares (folk sector) inclui especialistas não profissionais da cura, como ligados a grupos religiosos e seculares; e o setor informal (popular sector) inclui a família, a comunidade e todo tipo de atividade e de apoios de redes sociais ${ }^{65}$.

\section{Metamétodo}

As técnicas de produção e análise de dados utilizados nas pesquisas foram variadas. As entrevistas (semiestruturada ou em profundidade) $\mathbf{1 7 , 1 9 , 2 0 , 2 6 , 2 8 - 3 4 , 3 8 - 4 0 , 4 3 - 5 3 , ~ 5 5 , ~ 5 7 , 5 9 - 6 3 ~ f o r a m ~}$ as mais empregadas nos estudos, seguidas por etnografia ${ }^{35,48,64}$, diário de campo ${ }^{54}$, observação participante ${ }^{48,63}$, análise documental ${ }^{23} \mathrm{e}$ grupo focal27,62.

Os referenciais teóricos adotados pelos autores foram a Antropologia interpretativa, de Geertz ${ }^{\mathbf{7 7}, \mathbf{4 8 , 6 6}}$ (sustenta-se nos parâmetros originários da antropologia simbólica interpretativa, embasados na hermenêutica, com uma construção intelectual fundamentada em uma atmosfera de diversidade e pluralismo); a antropologia médica, de Kleiman 11,17,24,27,28,

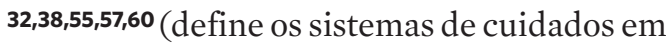
três setores ou subsistemas: o setor da cura profissional, o setor das curas populares e o setor popular das crenças, escolhas, decisões, papéis, relacionamentos, interações e instituições ${ }^{65}$ ); a socioantropologia da saúde, de Paulo César Alves 17,22,24,27,30,32, 34,36,45,55,57,64 (define os IT como os processos pelos quais os indivíduos ou grupos sociais escolhem, avaliam e aderem a determinadas formas de tratamento ${ }^{65}$ ); Dorothéa Orem ${ }^{28}$ (norteadora da sistematização dos cuidados de enfermagem, que define a teoria do autocuidado em prática de atividades que o indivíduo inicia e executa em seu próprio benefício, na manutenção da vida, da saúde e do bem-estar28).

Dos artigos selecionados, seis $\mathbf{1 5 , 2 9 , 3 1 , 4 4 , 4 6 , 5 5}$ utilizaram programas destinados à organização e à análise de dados qualitativos, com destaque para o NVivo (QRS International Pty, Doncaster, Austrália) e o Atlas.ti (Muhr T. Scientific software development $\mathrm{GmbH}$, Berlim, Alemanha).

As técnicas metodológicas de análises de dados também foram variadas. Entre elas, sobressaíram a Análise de conteúdo $11,17,24,26,28,37,38,40,43,50,54,55,57,59,60,62,63$, Genogramas ${ }^{57}$, Análise do discurso ${ }^{43}$, Análise temática ${ }^{21,29,27,32-34,46,55}$ e Análise institucional ${ }^{61}$. 
Alguns estudos não mencionaram as técnicas

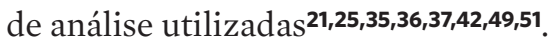

A avaliação do rigor metodológico, segundo os critérios Casp, constatou que $68,8 \%$ dos artigos foram classificados como B (moderado rigor metodológico). A análise de dados não rigorosa e a interação entre pesquisador e os participantes em campo formam os itens que pontuaram negativamente e contribuíram para o moderado rigor metodológico (gráfico 2).

Gráfico 2. Sumarização do rigor metodológico global de estudos selecionados para revisão e metassíntese sobre itinerários terapêuticos no Brasil (2008-2019)

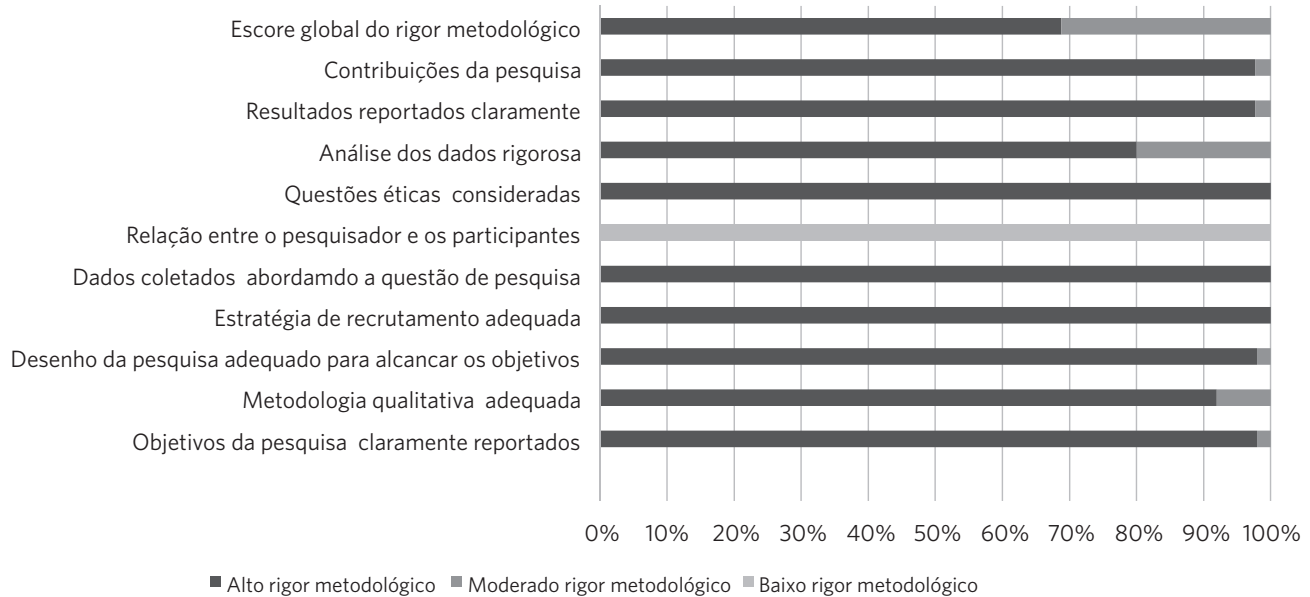

\section{Meta-análise}

Os caminhos percorridos pelos sujeitos na tentativa de solucionar algum problema de saúde são carregados de significados e mediados pelas experiências, inseridos em complexas redes de relações sociais. A construção de IT mobiliza saberes populares, religiosos e os conhecimentos biomédicos por meio do serviço público de saúde, revelando, dessa maneira, a existência de uma pluralidade terapêutica, com a finalidade de alcançar a 'saúde' ou a 'cura'36,39,41. Outros setores de cuidado, que não o formal, foram identificados no estudo de Segata e Segata ${ }^{\mathbf{4 2}}$, segundo o qual as práticas de cuidados e IT são constituídos por saberes tradicionais, espirituais, religiosos e de outras ordens diversas, podendo englobar desde as ditas garrafadas, os chás, os benzimentos, os descarregos, as orações e outras práticas religiosas até o emergente uso de medicinas integrativas, a exemplo das terapias com florais, pedras quentes, ou ainda da procura de literatura de autoajuda.

A busca de outros setores de cuidado explica-se, sobretudo, pelo fato de as pessoas encontrarem no curandeiro, por exemplo, ao contrário do que encontram no profissional médico, alguém que tem uma experiência de vida semelhante, que fala a mesma linguagem e pode compreendê-las ${ }^{\mathbf{5 2}}$. Tais significados corroboram os achados de Souza et al. ${ }^{\mathbf{4 8}}$ sobre os IT de travestis da região central do Rio Grande do Sul, Brasil, as quais recorrem às "casas de religião afro-brasileiras" e às Mães e Pais de Santos por identificá-los como espaços e figuras cuidadoras e acolhedoras, que, sem questionar as modificações corporais e sua 
identidade de gênero, oferecem formas satisfatórias de cuidado e proteção, permitindo às travestis a construção de IT que escapem dos processos de normatização dos corpos e da saúde.

Thaines et al. ${ }^{49}$ realizaram estudo com objetivo de compreender a trajetória empreendida por uma pessoa com Diabetes Melittus, adotando a perspectiva da integralidade da atenção à saúde. Segundo esses autores, a busca do cuidado ocorreu apenas no sistema formal e foi movida pelo sentimento de descrença com relação às possibilidades de resolver o problema de saúde. As necessidades de saúde não foram atendidas e, muito menos, compreendidas com relação, por exemplo, ao seu 'sentir-se mal' com o uso de insulina, o que levou a pessoa a continuar sua busca de cuidado em outros setores.

Se, por um lado, a literatura científica evidencia que a postura da biomedicina é marcada pela exclusão, dominação, restrição, redução, demarcação e normalização dos corpos nos processos de cuidado em saúde, por outro, a terapêutica religiosa tem se mostrado uma das alternativas de cuidado e cura integradora. Isso porque a adesão por parte de seus seguidores é influenciada por experiências individuais ou coletivas de sua eficácia e/ou pela fidelidade a uma religião que regula a vida em geral, incluindo as condutas relativas ao cuidado com o corpo e com a saúde ${ }^{29,48}$.

Nesse sentido, Trad et al. ${ }^{47}$, Ferreira e Espírito Santo ${ }^{23}$, Burille e Gerhardt ${ }^{29}$ demonstram em seus estudos uma classificação, de acordo com a experiência do sujeito, sobre quais problemas o levam a buscar os distintos setores de cuidado à saúde. Os problemas foram classificados em 'leves' e 'graves'. Aqueles problemas classificados como 'leves' são os que fazem o sujeito a buscar o cuidado no sistema informal, a exemplo de gripe, cefaleia etc. Enquanto os problemas classificados como 'graves' são os que exigem o cuidado formal (dos profissionais oficiais de saúde), no caso de diabetes, hipertensão, entre outros.

Os IT compreendem, ainda, os múltiplos sentidos que os sujeitos atribuem ao processo saúde-doença-cuidado. Para mulheres com câncer de colo uterino, por exemplo, os sentidos atribuídos à saúde foram determinantes da não realização de exames preventivos de Papanicolau, pois o conceito de saúde estava atrelado à ausência de perturbação física e/ ou psíquica e a ter disposição, e, enquanto não houvesse algum desequilíbrio entre esses três fatores, não fazia sentido para elas percorrerem um itinerário em busca de cuidados preventivos ${ }^{37}$. Já no estudo realizado por Neves e Nunes ${ }^{33}$, ainda que os sujeitos identificassem algum desequilíbrio orgânico, observou-se que, no início dos sintomas e no curso da doença, as pessoas tenderam a vivenciar a experiência do 'calar', negando a sua condição, mascarando a sua dor e outros sofrimentos, por meio do uso de medicação e de recursos fisioterapêuticos, e mimetizando um tipo ideal de trabalhador que está sempre capacitado a atender às demandas do sistema produtivo e que é infalível ao adoecimento. A automedicação e a busca do 'farmacêutico' foram destacadas nos estudos de Martins e Iriart ${ }^{\mathbf{3 0}}$ e Nabão e Maruyama ${ }^{\mathbf{3 2}}$, respectivamente, como forma de resistência à entrada no setor formal e como meio de passagem do tratamento popular para o sistema terapêutico formal.

Entre as principais redes de apoio aos IT, a família e os serviços de saúde se destacaram com papel importante na realização, avaliação e seleção de cuidados. Para Fundato ${ }^{24}$, o suporte familiar é o maior influenciador, determinador e avaliador dos cuidados estabelecidos e foi o primeiro acionado na busca de tratamento de pacientes com osteossarcoma. Entretanto, segundo Mângia e Yasutak ${ }^{25}$, essa relação com a família se mostrou ambígua, pois ora era considerada como fonte de auxílio, ora como razão de recaídas. Cordeiro et al.57, Corrêia et al. ${ }^{58}$ e Marques e Mângia ${ }^{27}$, apesar de encontrarem forte influência do sistema formal de cuidado nos IT das pessoas que vivenciam uma condição de adoecimento crônico, identificaram como recorrente a referência à adoção de cuidados domésticos para manutenção do bem-estar e enfrentamento da doença. Nessa 
direção, Amaral et al. ${ }^{17}$, ao investigarem o IT no cuidado mãe-filho, com interfaces entre a cultura e a biomedicina, questionam o que a família pondera para decidir quem ou que tipo de ajuda buscar com relação ao cuidado. Para as mães desse estudo, é importante levar em consideração sua opinião, o bom senso, o diálogo com familiares, parceiro, vizinhos e com pessoas que já vivenciaram situações semelhantes.

A resolubilidade do sistema formal também foi destacada nos estudos de Sisson et al.46, sobretudo no campo da saúde mental e da oncologia, cuja categoria 'satisfação' mostrou boa avaliação no infarto agudo do miocárdio, câncer de mama e parto, pela presença de acesso rápido a recursos técnicos adequados. Conill et al. ${ }^{56}$ identificaram em seu estudo um mix público-privado no sistema profissional de cuidados. Já Favero-Nunes e Santos ${ }^{24}$ revelaram a expansão da trajetória para outras especialidades, como a psicologia, a fonoaudiologia e a educação, e cita ainda uma 'força' do modelo biomédico na medicalização do transtorno autista na perspectiva de uma 'doença' a qual se pode tratar, curar e retornar (ou aceder) à normalidade através do sistema formal.

A integralidade aparece desde o prisma da concepção positiva de saúde no estudo de Ferreira e Silva ${ }^{21}$ sobre o IT de pessoas que convivem com HIV/Aids, no qual os profissionais de saúde se mostraram envolvidos com os dramas socioculturais dos sujeitos, construindo uma relação de cumplicidade, geradora de vínculo e confiança, que contribuiu significativamente para a adesão aos tratamentos. No cuidado integral, a pessoa é entendida na sua totalidade, considerando os aspectos biológicos, psicológicos, econômicos e socioculturais. Assim, a assistência médica integral, mesmo na dimensão individual, apresenta uma abordagem ampliada, valorizando as interações entre os sujeitos e a construção de vínculos na atenção entre os usuários do cuidado e os cuidadores ${ }^{43}$. Assim, pode-se inferir que a integralidade do cuidado em saúde-doença é fundamental na tomada de decisões à construção de IT, aproximando os processos de busca de cuidado e assistência da concepção positiva de saúde.

Não se observou nos artigos a abordagem ampliada sobre IT que transcendesse a mera noção de doença ou enfermidade ou adoecimento, ou que tivesse como ponto de partida processos preventivos de doenças e promotores de saúde. Diante disso, há ainda muito a avançar em pesquisas que abordem outras formas e itinerários de cuidados, que não apenas na iminência da doença ou do adoecimento - concepção negativa de saúde.

\section{Discussão}

A produção de estudos sobre IT no Brasil vem crescendo, porém, o foco desses estudos merece ser analisado e discutido ${ }^{10}$. A abordagem metodológica de pesquisa mais utilizada nos estudos sobre os IT foi a qualitativa. Esta abordagem se aplica ao estudo das relações, representações, crenças, percepções, subjetividades, produtos das interpretações que as pessoas fazem a respeito de como vivem ${ }^{67}$.

A maioria dos estudos selecionados para essa metassínte apoia-se no conceito de IT ligado aos 'cuidados médicos/terapêuticos à saúde', direcionado a compreender os resultados de atividades desenvolvidas pelos atores na busca de tratamento médico. Tratase de uma concepção que tende fortemente a estabelecer um caráter direcional, quase teleológico, às ações que os atores realizam para lidar com a doença e buscar cuidados. Tal concepção deve-se, em grande parte, à forma que usualmente os entrevistados/informantes reconstituem seu IT ${ }^{68}$. Essa abordagem está apoiada na concepção negativa de saúde e IT, que desconsidera o cuidado à saúde na sua perspectiva existencial, e dá ênfase somente aos procedimentos terapêuticos para tratar a doença e alcançar a cura.

Segundo Souza e Alves ${ }^{65}$, os estudos sobre itinerário terapêutico não devem ficar restritos à análise da disponibilidade de serviços, de seus modelos explicativos e nem tampouco 
da utilização que os indivíduos fazem das agências de cura. Conforme esses autores, tais elementos são insuficientes para a compreensão do complexo processo de escolha do tratamento, tornando-se necessário considerar o contexto sociocultural no qual o itinerário terapêutico ocorre.

Por meio dessa metassíntese, observa-se que as discussões sobre IT estão situadas, de um lado, por estudos que trazem uma perspectiva individual, com ênfase nas escolhas que o sujeito realiza, e, de outro, por estudos em que o contexto sociocultural é o determinante que predomina nas escolhas possíveis para o sujeito. Entretanto, os estudos mais recentes trazem uma perspectiva que vêm relativizando esse determinismo, tanto dos sujeitos como da cultura, no desenho dos IT, apresentando, cada vez mais, a articulação desses dois eixos ${ }^{69}$. É nesse sentido que Gadamer ${ }^{70}$ argumenta sobre o caráter holístico da saúde - por vezes oculto - e enfatiza que o objeto-modelo 'saúde' deve incorporar o componente metassintético e crítico-epistemológico na sua construção, respeitando a sua integridade-totalidade.

Ao contrário dos demais estudos 17,1934,40,51,53,55-59, para conhecer e analisar os IT dos indivíduos, algumas investigações ${ }^{35-38}$ levaram em consideração os significados e signos coletivos e individuais dos envolvidos no cuidado à saúde e cuidados médicos/terapêuticos, antes mesmo do acometimento de alguma doença ou enfermidade. Essa abordagem é recente em estudos sobre IT e segue o viés da concepção positiva de saúde, que busca abranger diversas dimensões do/no cuidado.

Destarte, a ontologia existencial de Heidegger (2005) ${ }^{\mathbf{7 1}}$ recorre à expressão 'Cuidado', tão amplamente usada na saúde para se referir às relações dessa centralidade dos projetos no modo de ser dos humanos, com os modos de compreenderem a si e a seu mundo e com seus modos de agir e interagir ${ }^{\mathbf{7 2}}$. Por isso, será denominada 'Cuidado a saúde' essa conformação humanizada do ato assistencial, distinguindo-a daquelas que, por razões diversas, não visam a essa ampliação, a exemplo do termo ‘Terapêutico', que remete a uma terapia, oferta de serviços, adesão a um tratamento e controle de uma doença. Adota-se aqui a expressão 'Cuidado a saúde' como designação de uma atenção à saúde imediatamente interessada no sentido existencial da experiência humana, e não apenas no adoecimento, físico ou mental, e, por conseguinte, também das práticas de promoção e proteção à saúde ${ }^{\mathbf{7 1}, \mathbf{7 2}}$.

A principal limitação deste estudo é a não investigação de dissertações e teses brasileiras sobre IT, restringindo-se à análise da produção científica publicada no formato de artigos científicos. Deve-se considerar, também, que o recorte temporal adotado (2008-2019) contempla uma parcela dos estudos publicados sobre o tema, no entanto, contempla o auge das pesquisas qualitativas sobre a temática deste estudo. Em contrapartida, nossa revisão sistemática apresenta rigor metodológico em todas as etapas do estudo, realizada por revisores independentes. Ressalta-se, ainda, a realização da avaliação da qualidade metodológica dos estudos analisados, sendo em sua maioria classificados como moderados. Por fim, sugere-se que os próximos estudos sobre o IT considerem os pontos limitantes dos estudos analisados, a exemplo da análise não rigorosa de dados e da ausência de descrição e discussão sobre a interação entre pesquisador e os participantes em campo, além da consideração de outras epistemologias sanitárias. Propõe-se, ainda, a ampliação dos horizontes de análise para além da experiência da doença e da enfermidade. É mister compreender os elementos que direcionam para uma apreensão ampliada da vida e do entendimento da saúde em sua concepção mais ampliada e positiva nos processos que envolvem a saúde, o adoecimento e o cuidado.

\section{Considerações finais}

Conclui-se que a produção de estudos acerca do tema Itinerários Terapêuticos apresenta grandes potencialidades para o setor saúde e 
para o campo de saberes e práticas em saúde coletiva. Conhecer o IT em seus percursos teórico-metodológicos pode possibilitar a apreensão de discursos e práticas que expressam diferentes lógicas, através das quais os princípios da integralidade e da resolutividade na atenção em saúde podem ser questionados. Além disso, os estudos em IT podem subsidiar uma prática avaliativa em saúde que privilegia a experiência de saúde ou adoecimento, bem como a busca de cuidados de usuários e suas famílias. Assim, a ampliação de referenciais de análise e perspectivas teóricas nos estudos sobre IT, a exemplo da concepção positiva de saúde, pode contribuir para ampliar o debate e o conhecimento na saúde coletiva sobre a efetividade da integralidade e a eficácia simbólica no cuidado em saúde.

\section{Colaboradores}

Demétrio F (0000-0001-8231-3307)*, Santana ER (0000-0002-0115-9553)*, Pereira-Santos M (0000-0003-3766-2502)* contribuíram igualmente para a elaboração do manuscrito.

\section{Referências}

1. Alves PC, Souza, IM. Escolha e avaliação de tratamento para problemas de saúde: considerações sobre o itinerário terapêutico. In: Rabelo MC, Alves PCS, Souza IM, organizadores. Experiência de Doença e Narrativa. Rio de Janeiro: Fiocruz; 1999. p. 125-38.

2. Almeida Filho N. For a General Theory of Health: preliminary epistemological and anthropological notes. Cad. Saúde Pública. 2001;17(4):753-70.

3. Luz MT. Complexidade do campo da saúde coletiva: Multidisciplinaridade, interdisciplinaridade, e transdisciplinaridade de saberes e práticas - Análise sócio-histórica de uma trajetória paradigmática. Saúde e Soc. 2009; 18(2):304-11.

4. Czeresnia D. The concept of health and the difference between prevention and promotion. Cad. Saúde Pública. 1999; 15(4):701-709.
5. Demétrio F, Paiva JB, Fróes AAG, et al. A nutrição clínica ampliada e a humanização da relação nutricionista-paciente: Contribuições para reflexão. Rev. Nutr. 2011; 24(5):743-63.

6. Teixeira CFS, Coelho MTÁD, Rocha MND. Bacharelado interdisciplinar: uma proposta inovadora na educação superior em saúde no Brasil. Ciênc. Saúde Colet. 2013; 18(6):1635-46.

7. Almeida Filho N. O conceito de saúde: ponto-cego da epidemiologia? Rev. Bras. Epidemiol. 2000; 3(13):4-20.

8. Camargo Jr. KR. As armadilhas da "concepção positiva de saúde”. Physis Rev. Saúde Coletiva. 2007; 17(1):63-76.

${ }^{\star}$ Orcid (Open Researcher 9. Batistella C. Abordagens contemporâneas do concei- 
to de saúde. In: Fonseca AF, Corbo AD, organizadores. O território e o processo saúde-doença. Rio de Janeiro: Fiocruz; 2007. p. 51-86.

10. Cabral ALLV, Martinez-Hemáez A, Andrade EIG, et al. Itinerários terapêuticos: o estado da arte da produção científica no Brasil. Ciênc. Saúde Colet. 2011; 16(11):4433-4442.

11. Guerin GD, Rossoni E, Bueno D. Itinerários terapêuticos de usuários de medicamentos de uma unidade de Estratégia de Saúde da Família. Ciênc. Saúde Colet. $2012 ; 17(11): 3003-10$.

12. Walsh D, Downe S. Meta-synthesis method for qualitative research: A literature review. Journal of Advanced Nursing. 2005; 50:204-11.

13. Spadacio C, Castellanos MEP, Barros NF, et al. Medicinas Alternativas e Complementares: uma metassíntese. Cad. Saúde Pública. 2010; 26(1):7-13.

14. Appraisal C, Programme S. Critical Appraisal Skills Programme (CASP). 10 Questions To Help You Make Sense of Qualitative Research. [internet]. CASP Qualitative Checklist. 2013. p. 1-6. [acesso em 2019 dez 18]. Disponível em: http://www.casp-uk.net/\#!untitled/ $\operatorname{cd} 2 \mathrm{~g}$.

15. Espindola CR, Blay SLB. Percepção de familiares sobre a anorexia e bulimia: revisão sistemática. Rev. Saúde Pública. 2009; 43(4):707-16.

16. Ring N, Jepson R, Ritchie K. Methods of synthesizing qualitative research studies for health technology assessment. Int J Technol Assess Health Care. 2011; 27(4):384-90.

17. Amaral RFC, Souza T, Melo TAP, et al. Itinerário terapêutico no cuidado mãe-filho: interfaces entre a cultura e biomedicina. Rev. Rene. 2012; 13(1):85-93.

18. Bomfim OL, Coser O, Moreira MEL. Unexpected diagnosis of fetal malformations: therapeutic itineraries. Physis. 2014; 24(2):607-22.

19. Fausto MCR, Campos EMS, Almeida PF, et al. The- rapeutic itineraries for patients with cerebrovascular accident: fragmentation of care in a regionalized health network. Rev. Bras. Saúde Matern. Infant. 2017; 17(supl1):S63-72

20 Favero-Nunes MA, Santos MA. Itinerário terapêutico percorrido por mães de crianças com transtorno autístico. Psicol. Reflexão e Crítica. 2010; 23(2):20821.

21. Ferreira DC, Silva GA. Caminhos do cuidado: itinerários de pessoas que convivem com HIV. Ciênc. Saúde Colet. 2012; 17(11):3087-98.

22. Ferreira J, Espírito Santo W. Os percursos da cura: abordagem antropológica sobre os itinerários terapêuticos dos moradores do complexo de favelas de Manguinhos, Rio de Janeiro. Physis. 2012; 22(1):179-98.

23. Finco M, Hennemann Bertoncini J. Itinerário terapêutico e vivência dos familiares e adolescentes com diabetes mellitus tipo 1. Rev. Bras. Promoç. Saúde. 2016; 29(3): 371-379.

24. Fundato C, Petrilli A, Dias Gutiérrez. Therapeutic Itinerary of Teenagers and Young Adults with Osteossarcoma. Brazilian J Oncol. 2012; 58(2):197-208.

25. Mângia EF, Yasutaki PM. Itinerários terapêuticos e novos serviços de saúde mental. Rev. Ter. Ocup. 2008; 19(1):61-71.

26. Landim DMP, Sarmento SS, Da Silva Filho CC, et al Itinerário terapêutico: a busca por cuidados de mães cujos filhos faleceram com menos de um ano. Rev. Pesqui. Cuid. Fundam. 2016; 8(3):4803-4812.

27. Marques ALM, Mângia EF. Itinerários terapêuticos de sujeitos com problemáticas decorrentes do uso prejudicial de álcool. Interface. 2013; 17(45):433-44.

28. Rosa LM, Radünz V. Itinerário terapêutico no câncer de mama: uma contribuição para o cuidado de enfermagem. Rev. Enferm. UERJ. 2013; 21(1):84-9.

29. Burille A, Gerhardt TE. Doenças crônicas, problemas crônicos: encontros e desencontros com os serviços 
de saúde em itinerários terapêuticos de homens rurais. Saúde e Soc. 2014; 23(2):664-76.

30. Martins PV, Iriart JAB. Itinerários terapêuticos de pacientes com diagnóstico de hanseníase em Salvador, Bahia. Physis. 2014; 24(1):273-89.

31. Musquim A, Filomena L, Araújo S, et al. Genograma e ecomapa: desenhando itinerários terapêuticos de família em condição crônica. Rev. Eletrônica Enferm. 2013; 15(3):656-66.

32. Nabão, FRZ, Maruyama SAT. A experiência da enfermidade e o itinerário terapêutico vivenciado por uma pessoa com infarto. Rev. Eletr. Enf. 2009; 10111(1):101-9.

33. Neves RF, Nunes MO. From legitimation to (re-)signification: the therapeutic itinerary of workers with RSIs/WMSDs. Ciênc. Saúde Colet. 2010; 15(1):211-20.

34. Nogueira LMV, Teixeira E, Basta PC, et al. Therapeutic itineraries and explanations for tuberculosis: an indigenous perspective. Rev. Saúde Pública. 2015 [acesso em 2019 dez 18]; 49:96.

35. Pereira MO, Sá MC, Miranda L. Um olhar sobre a atenção psicossocial a adolescentes em crise a partir de seus itinerários terapêuticos. Cad. Saúde Pública. 2014; 30(10):2145-54.

36. Pinho PA, Pereira PPG. Itinerários terapêuticos: trajetórias entrecruzadas na busca por cuidados. Interface. 2012; 16(41):435-50.

37. Ribeiro MGM, Santos SMR, Teixeira MTB. Therapeutic Itinerary of Women with Cervical Neoplasms: an Approach Focused on Prevention. Rev. Bras. Cancerol. 2011; 57(4):483-91.

38. Portugal CM. Entre o consultório e o terreiro: mediações, ruídos e silenciamentos nos itinerários terapêuticos de adeptos do candomblé. RECIIS. 2016; 10(1):1-14.

39. Santos RC, Silva MS. Condições de vida e itinerários terapêuticos de quilombolas de Goiás. Saúde Soc. 2014; 23(3):1049-63.
40. Carneiro DF, Silva MMB, Pinheiro M, et al. Itinerários terapêuticos em busca do diagnóstico e tratamento da hanseníase. Rev. Baiana Enferm. 2017; 31(2):1-9.

41. Scheffer JC, Fialho I M, Scholze AS. Itinerários de cura e cuidado de idosos com perda auditiva. Saúde e Soc. 2009; 18(3):537-48.

42. Segata J, Segata JB. Os caminhos da cura: itinerários terapêuticos e práticas populares de saúde no Alto Vale do Itajaí Santa Catarina. Rev. Caminhos. 2011; 1:7-24.

43. Silva DC, Budó MLD, Schimith MD, et al. Influência das redes sociais no itinerário terapêutico de pessoas acometidas por úlcera venosa. Rev. Gauch. Enferm. 2014; 35(3):90-6.

44. Silva LAV, Santos M, Dourado I. Entre idas e vindas: histórias de homens sobre seus itinerários ao serviço de saúde para diagnóstico e tratamento de HIV/ Aids. Physis. 2015; 25(3):951-73.

45. Silva NEK, Freitas HAG, Sancho LG. Da apreensão de informações aos itinerários terapêuticos de homens diante de suspeita ou com diagnóstico de infecções sexualmente transmissíveis. A internet em pauta. Physis. 2016; 26(2):669-89.

46. Sisson MC, Oliveira MC, Conill EM, et al. Satisfação dos usuários na utilização de serviços públicos e privados de saúde em itinerários terapêuticos no Sul do Brasil. Interface. 2011; 15(36):123-36.

47. Soares CS, Ripardo RC, Tavares JSC, et al. Itinerários terapêuticos face à hipertensão arterial em famílias de classe popular. Cad. Saúde Pública. 2010; 26(4):797-806.

48. Souza MHT, Signorelli MC, Coviello DM, et al. Itinerários terapêuticos de travestis da região central do Rio Grande do Sul, Brasil. Ciênc. Saúde Colet. 2014 [acesso em 2019 dez 6]; 19(7):2277-86. Disponível em: http://www.scielo.br/scielo.php?script=sci_arttext\& pid=S1413-81232014000702277.

49. Thaines GH de LS, Bellato R, Faria APS, et al. A busca 
por cuidado empreendida por usuário com diabetes mellitus: um convite à reflexão sobre a integralidade em saúde. Texto Context. Enferm. 2009; 18(1):57-66.

50. Valdanha-Ornelas ÉD, Santos MA. O Percurso e seus Percalços: Itinerário Terapêutico nos Transtornos Alimentares. Psicol. Teor Pesqui. 2016; 32(1):169-79.

51. Carvalho MB, Val AC, Ribeiro MMF, et al. Itinerários terapêuticos de sujeitos com sintomas anoréxicos e bulímicos. Ciênc. Saúde Colet. 2016; 21(8):2463-74.

52. Visentin A, Lenardt MH. O itinerário terapêutico: história oral de idosos com câncer. Acta Paul Enferm. $2010 ; 23(4): 486-92$.

53. Bueno D, Guerin GD, Rossoni E. Itinerários terapêuticos de usuários de medicamentos em uma Unidade de Estratégia de Saúde da Família. Rev. APS. 2014; 17(1):3003-3010

54. Rodrigues M, Maksud I. Abandono de tratamento: itinerários terapêuticos de pacientes com HIV/Aids Saúde debate. 2017; 41(113):526-38.

55. Cerqueira MMF, Alves RO, Aguiar MGG. Experiências vividas por mães de crianças com deficiência intelectual nos itinerários terapêuticos. Ciênc. Saúde Colet. 2016; 21(10):3223-32.

56. Conill EM, Pires D, Sisson MC, et al. O mix público-privado na utilização de serviços de saúde: um estudo dos itinerários terapêuticos de beneficiários do segmento de saúde suplementar brasileiro. Ciênc. Saúde Colet. 2008; 13(5):1501-10.

57. Cordeiro RC, Ferreira SL, Santos FC, et al. Itinerários terapêuticos de pessoas com anemia falciforme face às crises dolorosas. Rev. Enferm. UERJ. 2013; 21(2):179-84.

58. Corrêa GHLST, Bellato R, Araújo LFS, et al. Itinerário terapêutico de idosa em sofrimento psíquico e família. Ciência, Cuid. Saúde. 2012; 10(2):274-83.

59. Eckhardt NS, Raupp L. Itinerários terapêuticos de usuários de drogas na região Sul do Brasil. Psicol.
Saúde Doença. 2017; 18(1):263-77.

60. Andrade MS, Vieira EM. Itinerários terapêuticos de mulheres com morbidade materna grave. Cad. Saúde Pública. 2018 [acesso em 2019 dez 18]; 34(7): Disponível em: https://www.scielosp.org/article/ssm/ content/raw/?resource_ssm_path=/media/assets / csp/v34n7/1678-4464-csp-34-07-e00091917.pdf.

61. Coqueiro JM, Oliveira AE, Figueiredo TAM. Itinerários terapêuticos de sujeitos com diabetes mellitus: linhas fortes e fracas. Rev. Enferm. UFPE line. 2018; 12(6):1554

62. Muñoz RLS, Silva AEVF, Dantas DI, et al. Itinerários terapêuticos de pessoas com fibromialgia até um centro de tratamento da dor: um estudo qualitativo. ABCS Heal Sci. 2018 [acesso em 2019 dez 18]; 43(3). Disponível em: https://www.portalnepas.org. br/abcshs/article/view/1087.

63. Vale AR, Vecchia MD. "UPA é nós aqui mesmo": as redes de apoio social no cuidado à saúde da população em situação de rua em um município de pequeno porte. Saúde e Soc. 2019; 28(1):222-34.

64. Scott RP, Lira LC, Matos SS, et al. Itinerários terapêuticos, cuidados e atendimento na construção de ideias sobre maternidade e infância no contexto da Zika. Interface. 2018; 22(66):673-84.

65. Rabelo MC, Alves PCB, Souza IMA. Escolha e avaliação de tratamento para problemas de saúde: considerações sobre o itinerário terapêutico. In: Rabelo MC, Alves PC, Souza IM, organizadores. Experiência de doença e narrativa. Rio de Janeiro: Fiocruz; 1999. p. $125-38$

66. Geertz C. A interpretação das culturas. Rio de Janeiro: LTC; 2008.323 p

67. Minayo MCS. O desafio do conhecimento: pesquisa qualitativa em saúde. Ciênc. Saúde Colet. 2007; 12(4):1087-8

68. Alves PC. Itinerário Terapêutico, cuidados à saúde e a experiência de adoecimento. In: Gerhardt TE, Pi- 
nheiro R, Silva Junior AG, editores. Itinerários Terapêuticos: integralidade no cuidado, avaliação e formação em saúde. Rio de Janeiro: CEPESC; 2016. p. $125-46$.

69. Bellato R, Araújo LFS, Castro P. O itinerário terapêutico como uma tecnologia avaliativa da integralidade em saúde. In: Pinheiro R, Silva Junior AG, Mattos RA, organizadores. Atenção básica e integralidade: contribuições para estudos de práticas avaliativas em saúde. Rio de Janeiro: CEPESC/IMS/UERJ/ABRASCO; 2008. p. 167-87.
70. Gadamer HG. O caráter oculto da saúde. Petrópolis: Vozes; 2006.

71. Heidegger M. Ser e tempo. Petrópolis: Vozes. 2005.

72 Ayres JR CM. O cuidado, os modos de ser (do) humano e as práticas de saúde. Saúde e Soc. 2008; 13(3):1629.

Recebido em 10/04/2019

Aprovado em 17/09/2019

Conflito de interesses: inexistente

Suporte financeiro: não houve 